\title{
PERCEPÇÃO DOCENTE SOBRE O ATENDIMENTO AO ESTUDANTE AUTISTA EM ESCOLAS DE FORMOSA-GO E PLANALTINA-DF
}

\author{
PERCEPCIÓN DEL PROFESOR EN SERVICIO AL ESTUDIANTE AUTISTA EN \\ ESCUELAS DE FORMOSA-GO Y PLANALTINA-DF
}

\author{
TEACHING PERCEPTION ABOUT SERVICE TO AUTISTIC STUDENTS IN \\ SCHOOLS OF FORMOSA-GO AND PLANALTINA-DF
}

\author{
Wellington Oliveira dos SANTOS ${ }^{1}$ \\ Anny Gabriellen Cardoso de BRITO2 \\ Lorraine de Souza FERREIRA ${ }^{3}$
}

RESUMO: Este trabalho apresenta estudo a respeito da percepção docente sobre atendimento oferecido a estudantes autistas em escolas públicas de Formosa-GO e de Planaltina-DF. O estudo foi feito em duas partes: 1) observações em sala de aula de duas escolas públicas regulares (uma em cada cidade); 2) aplicação de questionário a docentes de uma escola de ensino regular e uma escola de educação especial (uma em cada cidade). A partir das observações e respostas aos questionários, foi possível detectar que os professores tendem a focar nas limitações dos estudantes autistas e não em suas potencialidades, o que inferimos ser prejudicial para o processo de ensino e aprendizagem.

PALAVRAS-CHAVE: Estudantes autistas. Docentes. Educação.

RESUMEN: Este trabajo presenta un estudio sobre la percepción docente sobre el servicio ofrecido a estudiantes autistas en escuelas públicas de Formosa-GO y Planaltina-DF. El estudio se realizó en dos partes: 1) observaciones en el aula de dos escuelas públicas regulares (una en cada ciudad); 2) aplicación de un cuestionario a maestros de una escuela regular y una escuela de educación especial (una en cada ciudad). A partir de las observaciones y respuestas de los cuestionarios, fue posible detectar que los maestros tienden a centrarse en las limitaciones de los estudiantes autistas y no en su potencial, que inferimos que va en detrimento del proceso de enseñanza y aprendizaje.

PALABRAS CLAVE: Estudiantes autistas. Profesor. Educación.

ABSTRACT: This paper presents the result of a study about the teaching perception about the care offered to autistic students in public schools in Formosa-GO and Planaltina-DF. The study

\footnotetext{
${ }^{1}$ Universidade Estadual de Goiás (UEG), Formosa - GO - Brasil. Professor (UEG) e Professor Colaborador no Programa de Pós-Graduação em Direitos Humanos (UnB). Doutorado em Educação (UFPR). ORCID: https://orcid.org/0000-0002-3289-2483. E-mail: psicologowell@gmail.com

2 Universidade Estadual de Goiás (UEG), Anápolis - GO - Brasil. Licenciada em Pedagogia. ORCID: https://orcid.org/0000-0003-1735-334X. E-mail: annygabriellen@gmail.com

3 Universidade Estadual de Goiás (UEG), Anápolis - GO - Brasil. Licenciada em Pedagogia. ORCID: https://orcid.org/0000-0001-7570-1977. E-mail: lorrainef.1998@hotmail.com
} 
was carried out in two parts: 1) observations in the classroom of two regular public schools (one in each city); 2) applying a questionnaire to teachers from a regular school and a special education school (one in each city). From the questionnaires answers and observations, it was possible to detect that teachers tend to focus on the limitations of autistic students and not on their potential, which we infer to be detrimental to the teaching and learning process.

KEYWORDS: Autistic students. Teachers. Education.

\section{Introdução}

A Lei de Diretrizes e Bases da Educação Nacional de 1996 (LDB) estabelece a educação como direito de todos, e quanto aos estudantes com deficiência, esses têm direito a atendimento preferencialmente na rede regular de ensino, com apoio especializado quando necessário, e quando não possível integração em classes comuns o atendimento deve ocorre em classes especiais. Além disso, a LDB estabelece que o sistema de ensino deve assegurar a adequação dos currículos, métodos e recursos oferecidos pelas instituições de ensino as necessidades dos estudantes com deficiência (BRASIL, 1996). Por sua vez, a atual Base Nacional Comum Curricular (BNCC), estabelece que "os sistemas e redes de ensino e as instituições escolares devem se planejar com um claro foco na equidade, que pressupõe reconhecer que as necessidades dos estudantes são diferentes" (BRASIL, 2017, p. 15), ou seja, buscar de algum modo incluir os grupos que foram marginalizados historicamente, incluindo as pessoas com deficiência, sendo assim demonstra ter como princípio constitutivo a inclusão.

Entre as pessoas com deficiência, estão os estudantes com Transtorno do Espectro Autista (TEA). Além da LDB e da BNCC, a educação dos estudantes autistas também possui respaldo na Lei n. 12.764/2012, que institui a Política Nacional de Proteção dos Direitos da Pessoa com Transtorno do Espectro Autista e estabelece a necessidade do estudante autista possuir apoio especializado em sala de aula, quando necessário. De acordo com a Lei n. 12.764/2012 é considerada pessoa autista aquela portadora de síndrome caracterizada por:

I - deficiência persistente e clinicamente significativa da comunicação e da interação sociais, manifestada por deficiência marcada de comunicação verbal e não verbal usada para interação social; ausência de reciprocidade social; falência em desenvolver e manter relações apropriadas ao seu nível de desenvolvimento;

II - padrões restritivos e repetitivos de comportamentos, interesses e atividades, manifestados por comportamentos motores ou verbais estereotipados ou por comportamentos sensoriais incomuns; excessiva aderência a rotinas e padrões de comportamento ritualizados; interesses restritos e fixos (BRASIL, 2012). 
Essa descrição, presente também nas Diretrizes de Atenção à Reabilitação da Pessoa com Transtorno do Espectro do Autismo (2014), segue o Manual de Diagnóstico e Estatística dos Transtornos Mentais (DSM-5), referência padrão utilizada pelos profissionais da saúde para diagnosticar condições mentais e comportamentais. De acordo com Pinho (2015) a partir do DSM-5, o autismo se insere na categoria diagnóstica dos transtornos de neurodesenvolvimento, como uma subcategoria dos Transtornos do Espectro Autista.

Para a melhora na qualidade de vida dos autistas, Teixeira (2015) salienta que as intervenções em conjunto envolvem diversos profissionais, como psicopedagogo, terapeuta comportamental, fonoaudiólogo, etc.

Como parte do cotidiano de inúmeras crianças, o(a) professor(a) ${ }^{4}$ também é um profissional relevante para a criança autista. A escola é elemento importante para o desenvolvimento da criança autista, nos aspectos cognitivos, sociais, afetivos, psicomotores, entre outros. Por esse motivo, importa saber como ocorre a relação entre estudantes autistas e professores, e como os professores entendem o atendimento ofertado aos estudantes autistas nas escolas.

Considerando as especificidades dos estudantes autistas e os contextos em que estão inseridos, este trabalho apresenta o resultado de estudo exploratório sobre o atendimento oferecido a estudantes autistas em escolas públicas de Formosa - Goiás e de Planaltina Distrito Federal. A pesquisa teve como objetivo verificar diferenças entre o atendimento oferecido aos estudantes autistas das duas cidades e a percepção dos professores sobre o tema.

\section{Estudos sobre a inserção de estudantes autistas nas escolas}

Na nossa pesquisa, partimos do ponto de vista da psicologia histórico-cultural de Lev Vygotsky (1994; 1998) para o entendimento dos processos de ensino e aprendizagem. A psicologia histórico-cultural pressupõe uma concepção interacionista do desenvolvimento cognitivo dos seres humanos, privilegiando a mediação simbólica e a interação com o outro (STOLTZ, 2012). De acordo com Stoltz (2012) a ênfase de Vygotsky na mediação simbólica está diretamente relacionada ao papel da história e cultura na constituição psicológica dos seres humanos.

Para Vygotsky, os processos psicológicos superiores que distinguem os seres humanos dos animais, como a consciência e a capacidade de raciocínio, são resultado da história de

\footnotetext{
${ }^{4}$ A partir deste ponto usamos o genérico masculino.
} 
interações do sujeito com a sociedade e cultura desde seu nascimento (VYGOTSKY, 1994). Por isso Vygotsky dedicou atenção a educação formal, uma vez que na escola a criança tem a oportunidade de aprender os conceitos científicos a partir de seus conceitos cotidianos (VYGOTSKY, 1998). É na escola, além disso, que o professor pode atuar na zona de desenvolvimento proximal da criança, isto é, servindo como mediador entre o conhecimento real da criança e o seu conhecimento potencial.

A ênfase na mediação simbólica também deve estar presente na educação especial. De acordo com Costa (2006), a zona de desenvolvimento proximal permite interagir com o estudante da educação especial a partir de sua potencialidade, não de sua "limitação", com destaque para o papel da linguagem na interação. A autora destaca que a educação especial focada nas limitações dos estudantes tende à discriminação e ao preconceito, empobrecendo o universo dos estudantes. A educação de estudantes deficientes deve ter o mesmo objetivo da educação regular. O que precisa ser alterado são os meios para atingir tais objetivos, de acordo com as especificidades de cada estudante (COSTA, 2006).

Sobre os meios adequados, Trevizan e Pessoa (2018), em pesquisa com estudante autista, destacam que as mediações nos contextos familiares e escolares devem tanto atender as necessidades do sujeito com TEA bem como serem prospectivas, ou seja, favorecer seu desenvolvimento cognitivo. De acordo com os autores, a relação do estudante autista com o ambiente é mais direta do que mediada por símbolos, o que exige atenção aos meios materiais utilizados. Por exemplo, no estudo de caso com uma criança apresentado pelos autores, as relações entre as palavras e os conceitos abstratos precisava ser explicitada (muitas vezes com objetos materiais) para o entendimento da criança.

Infelizmente muitos professores podem não estar preparados para a presença de um estudante autista em sala de aula. Trevizan e Pessoa (2018) alertam que certos comportamentos das crianças autistas, como repetir ações, podem ser interpretados como simples atos mecanicistas pelos professores, levando-as a serem isoladas do resto da turma.

A respeito do entendimento do autismo por parte dos professores, Pimentel e Fernandes (2014) realizaram pesquisa com professores de escolas regulares e especiais que responderam questões baseadas nos aspectos de comunicação, socialização e comportamento apresentado pelas crianças autistas. As respostas indicam que os professores acreditavam que tinham que contribuir para a comunicação e as relações interpessoais dos estudantes. Constataram que as escolas forneciam assistência suficiente, mas havia déficits tanto em relação ao auxílio de outros profissionais como também tecnologias pertinentes para o ensino (PIMENTEL; FERNANDES, 2014). Entre as dificuldades, as principais respostas apontavam para a insuficiência na 
promoção da autonomia e da relação interpessoal. O estudo averiguou que há necessidade de uma escola com estrutura adequada, profissionais com qualificação apropriada, auxílio de uma equipe multidisciplinar, e também uma orientação e acompanhamento para que a inclusão seja efetiva.

Nessa linha de pensamento sobre a escolarização, Lima e Laplane (2016) a partir da análise dos micro dados do Censo da Educação Básica entre os anos de 2009 e 2012, no município de Atibaia/SP, investigaram situações de escolarização de estudantes autistas, examinando os tópicos sobre acesso e permanência e também analisaram a aquisição de apoios terapêuticos disponíveis. Os dados mostraram que existia uma grande evasão escolar desses estudantes, principalmente nas séries finais do Ensino Fundamental, e os que estavam devidamente matriculados não cursavam as turmas em que estavam inscritos. Possivelmente isso se deve pelo fato de que a rede estadual não disponibilizava apoio educacional especializado e pelo receio dos pais na mudança de modalidade de ensino.

Schmidt et al., (2016) analisaram a inclusão escolar de estudantes diagnosticados com TEA, por meio de sistematização de seis estudos que ocorreram entre os anos de 2013 e 2015, com a participação de 38 professores. Os resultados apontam que para que se tenha sucesso na inclusão escolar é primordial que os professores tenham uma concepção positiva no que se refere à relação com o estudante autista, tendo em consideração as necessidades individuais e a avaliação dos mecanismos eficientes para a aprendizagem. Quanto à prática pedagógica, as estratégias utilizadas pelos professores são aquelas que se utilizam de recursos visuais e do interesse da criança para o planejamento de aula (SCHMIDT et al., 2016). Outra temática foi a alfabetização do estudante com TEA, visto que os dados apontam que métodos tradicionais são ineficientes e existe uma dificuldade do professor em avaliar a aprendizagem. Embora a questão de socialização seja uma das mais importantes no contexto escolar inclusivo, é raramente destacada pelos professores e necessita ser discutida pois "a interação de educandos com autismo com outros colegas é limitada ou inexiste, fazendo que muitos manifestem comportamentos desadaptativos como uma tentativa de interação" (SCHMIDT et al., 2016, p. 230-231).

Nessa mesma perspectiva Martins e Monteiro (2017) observaram as interações sociais que ocorrem no ambiente escolar com a criança diagnosticada com TEA e a professora, com os demais colegas e com a pesquisadora, buscando compreender o processo de escolarização da criança. As pesquisadoras observaram uma sala de aula de Ensino Fundamental, em escola especial, constituída por quatro estudantes, três meninos e uma menina, diagnosticados com TEA. Observaram que a professora possuía dificuldades de interpretar as ações da criança com 
TEA quando eram diferentes do padrão normativo. Diante dessas situações, a professora buscava inibir o comportamento indesejado e retomar a normalidade. Desse modo, Martins e Monteiro (2017) frisam que existe uma centralidade nas dificuldades que são próprias do transtorno e não nas possibilidades de interação, e o foco educacional está em métodos que tendem a valorizar a execução de tarefas e inibição de comportamentos indesejados.

A presença de um profissional para atendimento ao estudante autista durante as aulas pode auxiliar nas interações desse no ambiente escolar. Vargas e Rodrigues (2018) frisam que o mediador escolar é capaz de reconhecer as múltiplas possibilidades para a inclusão e a individualidade do outro, fugindo da visão de anormalidade.

No aspecto escolarização, Rodrigues e Angelucci (2018) realizaram levantamento sobre a produção acadêmica acerca da escolarização dos indivíduos diagnosticados com TEA em classes regulares do Brasil. Em muitos dos trabalhos analisados as percepções dos professores sobre o TEA são estereotipadas. As temáticas das pesquisas giram em torno de temas como a prática pedagógica e a mediação dos professores com os estudantes autistas. As produções destacam pontos específicos, gerando uma variedade de interpretações com ênfase no que deveria fazer parte da escola e em como deve ser a experiência vivenciada no decorrer do desenvolvimento educacional; também salientam que o foco educativo está além dos diálogos que envolvem a aprendizagem e a socialização. Sendo assim, Rodrigues e Angelluci (2018) alertam que a escolarização de crianças com diagnóstico de TEA tem se constituído mais próxima a integração do que inclusão, pois possui relação com uma concepção de reabilitação, consequentemente há uma suposição de que o professor necessita de uma compreensão biomédica para realizar suas atividades educativas.

\section{Metodologia de pesquisa}

Trata-se de uma pesquisa de abordagem qualitativa, realizada em escolas de Formosa Goiás e de Planaltina - Distrito Federal. As duas cidades são separadas por uma distância de cerca de $40 \mathrm{~km}$. Foram feitas observações em duas instituições de ensino públicas nos meses de agosto e setembro de 2019. Para isso, selecionamos turmas do Ensino Fundamental I. As observações ocorreram em uma turma de $2^{\circ}$ ano na cidade de Formosa-GO; e uma turma de $3^{\circ}$ ano na cidade de Planaltina-DF. As turmas regulares foram selecionadas para a investigação pela presença de um estudante autista entre os estudantes. O tempo de observação: 4 horas em três dias distintos em cada turma, totalizando 12 horas de observação por turma. 
As observações incluíam anotações a partir de um roteiro de observação. O roteiro de observação destacava os seguintes pontos para anotações:

- $\quad$ Descrição das atividades propostas pela(o) professora(o);

- $\quad$ Recursos pedagógicos utilizados durante a aula;

- Interações entre estudantes e estudante autista;

- Interações entre professor(a) e estudante autista.

Além das observações, o estudo exploratório também contou com aplicação de questionário em duas escolas: uma escola de educação especial de Planaltina-DF e uma escola regular de Ensino Fundamental de Formosa-GO. O questionário foi uma adaptação do utilizado por Pimentel e Fernandes (2014), e seu objetivo foi entender a percepção dos professores sobre a presença do estudante autista em sala de aula e o processo de inclusão. Contava com questões de identificação do perfil do docente (sexo, idade, cor/raça, tempo de atuação como docente, escolaridade, se possui formação em educação especial), preservando o anonimato, e perguntas objetivas sobre as contribuições e as dificuldades na relação professor e estudante autista; e uma indagação discursiva sobre quais são os elementos que a escola oferece para o desenvolvimento do estudante.

Responderam o questionário 13 docentes: 6 da escola especial e 7 da escola regular; sendo 11 mulheres e 2 homens (um homem em cada instituição). A idade média dos respondentes foi acima de 40 anos. De acordo com os critérios do IBGE, considerou-se a cor/raça: 1 preto, 2 brancos, 9 pardos e um não respondeu. Considerando o tempo de atuação como professor, apenas 3 possuíam menos de 5 anos; 4 possuíam de 5 a 10 anos, e 6 mais de 11 anos. Quanto à escolaridade, uma distinção entre a escola regular e a escola especial deve ser considerada: na escola regular 3 docentes possuem pós-graduação e desses 2 possuem especialização em educação especial. Na escola especial, os 6 professores possuem pósgraduação, sendo que 5 possuem especialização em educação especial.

\section{Resultados e discussão}

\section{As observações}

As observações nas escolas regulares permitiram comparações. Os resultados não podem ser tomados como amostra representativa do atendimento oferecido no Ensino Fundamental público de ambas as cidades, já que as observações foram limitadas a uma turma em uma escola de cada cidade. Podem, entretanto, levantar questões para pesquisas futuras. 
A primeira comparação a ser feita é com relação a estrutura oferecida pelas escolas. A sala de recursos para os estudantes da escola de Formosa-GO é significativamente inferior à da escola de Planaltina-DF. A sala de recursos é usada para atendimento aos estudantes no contraturno das aulas.

Durante as observações em sala na turma de $2^{\circ}$ ano (Formosa-GO), o estudante autista foi auxiliado por uma estagiária do curso de Pedagogia, sem formação específica para atuar com esse público. Não houve atividades propostas exclusivamente para o estudante durante as observações.

Por outro lado, na turma de $3^{\circ}$ ano (Planaltina-DF), o estudante autista presente foi auxiliado principalmente pela professora regente da turma. A mesma auxiliava o estudante nos momentos em que não conseguia acompanhar a turma em uma atividade, promovendo a zona de desenvolvimento proximal. O estudante também solicitava ajuda quando possível. A professora utilizou materiais adaptados para os jogos. Em conversa posterior, a professora revelou que possui pós-graduação em educação especial. Como ela conhecia o estudante desde o ano anterior, sabia como auxiliá-lo durante as aulas. A turma não tinha professor auxiliar, e sim um monitor que uma vez por semana acompanhava as aulas. O monitor não tinha formação específica (formado em administração, atuava por ter passado em concurso público).

Aqui destacamos um atendimento melhor por parte da escola de Planaltina-DF. A professora realizou a mediação com o estudante a partir de materiais adaptados, o que Costa (2006) e Trevizan e Pessoa (2018) defendem como importante no processo de ensino e aprendizagem do autista. Entretanto, não sabemos se os resultados seriam os mesmos em uma turma sem professora especialista em educação especial. Por outro lado, em ambas as escolas o professional auxiliar não tinha formação para intervir com o estudante autista. No caso de Planaltina-DF mais grave, já que o monitor não tinha sequer estudo na área da educação.

Em um dos dias de observação na turma de $2^{\circ}$ ano (Formosa-GO), a turma realizou a Prova Brasil. Na aplicação da prova, a professora regente conduziu a leitura das questões para os estudantes, enquanto os mesmos respondiam. Enquanto isso, o estudante autista ficou sentado ao fundo, aguardando. Em outras aulas, a professora utilizou como recursos didáticos o quadro negro e o livro. Não foi oferecida por parte da professora regente atividade direcionada ao estudante autista. Isso foi comum em outros dias de observação: a estagiária de Pedagogia foi a pessoa que mais interagiu com o estudante. Muitas vezes o estudante autista permaneceu na sala sem qualquer atividade a ser feita, o que fazia com que ficasse agitado, levantando da carteira para conversar com os colegas. 
$\mathrm{Na}$ turma de $3^{\circ}$ ano (Planaltina-DF) foi possível constatar que o planejamento das atividades das aulas considerava o papel do estudante autista. Por exemplo, uma das atividades sobre palavras do cotidiano, a professora utilizou fotografias dos colegas de classe para melhor associação. A professora demonstrou preocupação em outros momentos, como nas atividades para reconhecer as cores, atividades com números e atividades motoras em geral. Durante as observações, as interações entre o estudante autista e os demais estudantes da sala foram positivas. $\mathrm{O}$ estudante participava das atividades em grupo propostas pela professora e nos momentos de brincadeira era chamado a participar pelos colegas.

Mais uma vez, a explicação plausível para a diferença de atendimento oferecido aos estudantes autistas e a condução das aulas nas diferentes turmas pode ser atribuída à formação da professora regente. Não podemos esquecer, porém, das condições de trabalho da professora que atua na turma de Formosa-GO, uma turma mais numerosa. A presença de uma professora auxiliar poderia solucionar parte da demanda, porém o que foi observado é que somente a estagiária, sem ainda ter formação adequada, estava à disposição. Isso prejudica a mediação, que muitas vezes precisa ser feita por profissional capacitado, conforme Vargas e Rodrigues (2018). A interação entre os estudantes autistas e os colegas de classe teve certa diferença. No caso de Planaltina-DF foi mais proveitosa, enquanto que em Formosa-GO, por não saber o que fazer em sala, muitas vezes o estudante autista ficava isolado dos outros.

\section{O questionário}

Tendo em vista melhor visualização dos dados obtidos no questionário, organizamos os mesmos em tabelas, de acordo com cada questão. As tabelas apresentam na coluna esquerda as opções disponíveis para a resposta, e na coluna direita as respostas escolhidas, separadas de acordo com a escola do professor respondente (regular - ER - ou especial - EE). Os professores podiam marcar mais de uma opção para as questões. Lembrando que responderam ao questionário 13 docentes: 7 da escola regular e 6 da escola especial.

A questão 1 "Em quais áreas você acredita que estimula e contribui para melhorar o desenvolvimento de seu aluno autista", sintetizada na tabela 1 , teve quase unanimidade dos docentes de ambas as instituições assinalando as áreas de "comunicação", "aprendizagem", “comportamento" e "autonomia". Nas opções "relações interpessoais" e "desenvolvimento psicomotor", menos da metade dos professores da escola regular assinalaram; por outro lado a opção "raciocínio" teve baixa adesão pelos docentes de ambas as escolas. 
Tabela 1 - Áreas que o professor acredita que estimula e contribui para melhorar o desenvolvimento do seu aluno autista

\begin{tabular}{lcc}
\hline Áreas & ER & EE \\
\hline Comunicação & 5 & 6 \\
\hline Aprendizagem & 5 & 6 \\
\hline Relações interpessoais & 3 & 6 \\
\hline Comportamento & 5 & 4 \\
\hline Desenvolvimento psicomotor & 2 & 6 \\
\hline Raciocínio & 3 & 2 \\
\hline Autonomia & 5 & 6
\end{tabular}

Fonte: elaborada pelos autores.

Analisando as opções assinaladas pelos docentes, é possível considerar que "comunicação", "aprendizagem", "comportamento" e "autonomia" são áreas que os professores acreditam (ou pelo menos esperam) contribuir não apenas com relação aos estudantes autistas, mas a todos os outros. Então o número de adesões a essas opções era esperado e vai ao encontro da pesquisa de Pimentel e Fernandes (2014). Por outro lado, ainda que a área "desenvolvimento psicomotor" tenha sido mais assinalada pelos docentes da educação especial (o que era esperado por possuírem formação específica e pela própria função da educação especial), causou estranhamento que menos da metade dos respondentes da escola regular tenham assinalado a opção "relações interpessoais", contrariando parte do resultado de Pimentel e Fernandes (2014). Considerando o conceito de zona de desenvolvimento proximal de Vygotsky (1998), que pressupõe as relações interpessoais para existir, isso pode significar falta de conhecimento por parte dos professores da importância das relações interpessoais para o desenvolvimento do estudante autista, principalmente as que envolvem o professor.

A questão 2 "Em quais áreas você encontra mais dificuldade com seu aluno autista", sintetizada na tabela 2, apresentava as mesmas opções da questão 1. As alternativas escolhidas pelos docentes foram distintas, de acordo com a escola. Enquanto que na escola regular as opções mais assinaladas foram "relações interpessoais", "aprendizagem" e "comportamento", na escola especial foram "comunicação", "relações interpessoais", “aprendizagem" e "autonomia". 
Tabela 2 - Áreas em que o professor encontra mais dificuldade com seu aluno autista

\begin{tabular}{lcc}
\hline Áreas & ER & EE \\
\hline Comunicação & 2 & 6 \\
\hline Aprendizagem & 3 & 4 \\
\hline Relações interpessoais & 4 & 5 \\
\hline Comportamento & 3 & 3 \\
\hline Desenvolvimento psicomotor & 1 & 3 \\
\hline Raciocínio & 2 & 3 \\
\hline Autonomia & 2 & 4 \\
\hline
\end{tabular}

Fonte: elaborada pelos autores.

Interpretando esses dados, é possível relacioná-los com as respostas a primeira questão. Se por um lado os professores da escola regular pouco assinalaram que contribuem para as "relações interpessoais", por outro lado foi a área mais assinalada por esses no que diz respeito a dificuldades encontradas, assim como na pesquisa de Pimentel e Fernandes (2014). A mediação tem importância em sala de aula, para o ensino de conceitos científicos (STOLTZ, 2012), e quando os professores afirmam que os estudantes autistas têm dificuldades nas relações interpessoais ao mesmo tempo em que não intervêm nessas relações podem estar culpabilizando a condição do autista, quando o que a escola deveria fazer é adequar-se as suas condições, como defendem Trevizan e Pessoa (2018). Outro ponto que merece reflexão é a área "comportamento". Qual comportamento os docentes dizem ter dificuldade? Infelizmente os dados não permitem dizer, mas é possível que os docentes da escola regular partam de uma visão normativa do que seria o comportamento adequado de um estudante em sala de aula.

A questão 3 "Em quais circunstâncias seu aluno autista se comunica", sintetizada na tabela 3, apresentou diferenças significativas nas respostas. Enquanto que na escola regular as opções mais assinaladas foram "para pedir informações, objetos, comentar fatos" e "para interagir com o professor e os colegas da sala", na escola especial foi "não focaliza o assunto".

Tabela 3 - As circunstâncias que o aluno autista se comunica

\begin{tabular}{lcc}
\hline \multicolumn{1}{c}{ Áreas } & ER & EE \\
\hline Para pedir informações, objetos, comentar fatos & 5 & 2 \\
\hline $\begin{array}{l}\text { Para interagir com o professor e os colegas da } \\
\text { sala }\end{array}$ & 5 & 1 \\
\hline Não focaliza o assunto & 4 & 4 \\
\hline Para protestar & 2 & 1 \\
\hline Nunca tenta se comunicar & 0 & 0 \\
\hline
\end{tabular}

Fonte: elaborada pelos autores. 
$\mathrm{Na}$ escola especial na qual foi feita a pesquisa, a maior parte dos estudantes com TEA não têm condições suficientes para ir à escola regular, o que explica os resultados para essa questão no que diz respeito aos professores dessa instituição. Por outro lado, os professores da escola regular assinalaram que os estudantes autistas se comunicam "para pedir informações, objetos, comentar fatos" e "para interagir com o professor e os colegas da sala", o que entra em conflito com suas respostas na questão 1, que pouco assinalaram "relações interpessoais" entre as áreas que acreditam contribuir com o desenvolvimento do estudante autista. Vygotsky (1998) defende que para o desenvolvimento cognitivo as interações realizadas com a linguagem são fundamentais, entretanto, ainda que reconheçam que os estudantes buscam interagir os professores pouco consideram sua contribuição na área de relações interpessoais.

A questão 4 "Em relação aos comportamentos e interesses, quais observa com mais frequência em seu aluno autista", sintetizada na tabela 4, apresentou resultados semelhantes quando comparamos os dois grupos de docentes. As opções mais escolhidas pelos docentes da escola regular foram "atende ordens", "Resiste em participar das atividades propostas e/ou mudanças de rotina" e "Mostra-se arredio e/ou indiferente". $\mathrm{Na}$ escola especial, as opções "Apresentou comportamentos estereotipados (repetição persistente de atos e/ou fala)", "atende ordens" e "Resiste em participar das atividades propostas e/ou mudanças de rotina" foram as mais escolhidas. É necessário cautela na interpretação das respostas dos professores da escola regular, pois como afirmam Schmidt et al., (2016) a falta de interação entre o estudante autista e os colegas de sala ou professores pode fazer com que esse estudante utilize comportamentos desadaptativos como forma de interação. Pode ser que os professores tenham dificuldades em interpretar o comportamento do estudante autista, conforme demonstra o estudo de Martins e Monteiro (2017). 
Tabela 4 - Comportamentos do aluno autista observado com mais frequência pelos professores

\begin{tabular}{llc}
\hline \multicolumn{1}{c}{ Áreas } & ER & EE \\
\hline Relaciona-se com colegas de sala & 2 & 0 \\
\hline Atende ordens & 5 & 4 \\
\hline $\begin{array}{l}\text { Resiste em participar das atividades propostas } \\
\text { e/ou mudanças de rotina }\end{array}$ & 5 & 4 \\
\hline Demonstra medos & 0 & 1 \\
\hline Utiliza pessoas como ferramentas & 1 & 3 \\
\hline Resiste ao contato físico & 3 & 3 \\
\hline $\begin{array}{l}\text { Mantém contato visual com professores } \\
\text { colegas }\end{array}$ & 2 & 1 \\
\hline $\begin{array}{l}\text { Apega-se a objetos de maneira inapropriada } \\
\text { e/ou gira objetos }\end{array}$ & 3 & 3 \\
\hline $\begin{array}{l}\text { Mostra-se arredio e/ou indiferente } \\
\text { Apresentou comportamentos estereotipados } \\
\text { (repetição persistente de atos e/ou fala) }\end{array}$ & 5 & 5 \\
\hline $\begin{array}{l}\text { Apresenta auto e/ou hetero agressão (bate nos } \\
\text { outros ou em si mesmo) }\end{array}$ & 3 & 3 \\
\hline
\end{tabular}

Fonte: elaborada pelos autores.

$\mathrm{Na}$ questão 5 do questionário, "O que oferecem de materiais, ambiente estimulador, encaminhamentos, para que ocorra o desenvolvimento de autistas?", a maior parte dos respondentes da escola regular afirmou que o estudante possui professor de apoio, jogos pedagógicos, fichas de leitura, alfabeto móvel, massinha de modelar, atividades no computador, atividades específicas para o seu desenvolvimento. Por exemplo:

Encaminhamento para psicóloga e fono. Estagiária de apoio para auxiliar nas tarefas. Número reduzido de alunos na sala de aula. Alguns materiais didáticos para trabalhar com a criança (material dourado, jogo de memória, fichas de leitura, formação de palavras, alfabeto móvel, etc.) (docente B).

Analisando as respostas para a escola regular, ainda que os docentes apontem para a existência de professor de apoio, número reduzido de estudantes em sala e materiais diversos nas aulas, algo semelhante ao estudo de Pimentel e Fernandes (2014), isso só ocorre nas atividades de contraturno do estudante, ao contrário do que foi observado nas escolas regulares de Planaltina-DF e principalmente Formosa-GO: estudantes autistas muitas vezes sem um mediador com formação adequada; e as aulas conduzidas utilizando somente o livro didático e o quadro negro como recurso. Como alertam Lima e Laplane (2016), o ambiente educacional adequado é necessário na prevenção da evasão escolar do estudante autista.

$\mathrm{Na}$ escola especial as respostas, de maneira geral, foram materiais concretos, rotina estruturada, passeios pela escola e pelo comércio, jogos e brinquedos, encaminhamento para 
equoterapia, materiais audiovisuais. Alguns docentes apontaram que as circunstâncias vão depender do que o estudante necessita.

Segundo relatos informais de professoras dessa escola especial, o objetivo dessa instituição é preparar o estudante para a escola regular, o mesmo foi observado por Rodrigues e Angelluci (2018), que perceberam que a escolarização dos estudantes com TEA é próxima do conceito de integração, no qual são os estudantes que devem se preparar para a escola. $\mathrm{O}$ problema ocorre, conforme o estudo de Martins e Monteiro (2017), quando a atenção é centralizada na deficiência da criança e não em sua potencialidade.

Sintetizando as respostas dos questionários, é possível afirmar que os professores da escola regular tendem a pouco privilegiar as relações interpessoais com os estudantes autistas, focando mais na "deficiência” que nas potencialidades desses. Ambos os grupos de professores demonstraram ter dificuldade nessa área, e podemos inferir que muitas vezes os professores da escola regular tendem a considerar as tentativas de interação dos estudantes autistas como "mau comportamento", já que entre os comportamentos que eles mais destacaram observar está "mostra-se arredio ou indiferente". E ainda que destaquem a existência de material de apoio e profissionais especializados no atendimento ao estudante autista, isso não condiz com o cotidiano das turmas regulares, como constatamos nas observações.

\section{Considerações finais}

Este artigo busca contribuir para o entendimento das relações existentes entre estudantes autistas e contextos educacionais. A partir das observações em sala de aula e as respostas aos questionários, emergiram questionamentos e inferências acerca das condições de ensino e aprendizagem dos estudantes autistas.

Uma vez que para o desenvolvimento da pessoa autista a educação formal é considerada fundamental, respaldada por legislação própria (por exemplo, a Lei n. 12.764/2012), foi preocupante constatar que a efetivação desse direito muitas vezes não ocorre devido as condições materiais das escolas ou as relações interpessoais entre professores e estudantes. A partir das respostas dos questionários e das observações, foi possível detectar que os professores das escolas regulares tendem a focar nas limitações dos estudantes autistas e não em suas potencialidades, o que inferimos ser prejudicial para o processo de ensino e aprendizagem.

Como trata-se de um estudo exploratório, os dados aqui analisados não podem ser tomados para generalização do quadro em ambas as cidades. Mas é possível tecer elementos para futuras pesquisas. Por exemplo, uma amostra significativa de escolas regulares e turmas 
em que estão presentes estudantes autistas para observações. Também maior amostra para a aplicação do questionário. Outro estudo relevante seria o levantamento dos professores que possuem formação em educação especial.

\section{REFERÊNCIAS}

BRASIL. Lei n. 9394, de 20 de dezembro de 1996. Estabelece as diretrizes e bases da educação nacional. Diário Oficial da União, Brasília, DF, 23 dez. 1996. Disponível em: http://www.planalto.gov.br/ccivil_03/leis/19394.htm. Acesso em: 23 jun. 2019.

BRASIL. Lei n. 12.764, de 27 de dezembro de 2012. Institui a Política Nacional de Proteção dos Direitos da Pessoa com Transtorno do Espectro Autista; e altera o $\S 3^{\circ}$ do art. 98 da Lei $n$. 8.112, de 11 de dezembro de 1990. Diário Oficial da União, Brasília, DF, 28 dez. 2012. Disponível em: https://presrepublica.jusbrasil.com.br/legislacao/1033668/lei-12764-12. Acesso em 25 jun. 2019.

BRASIL. Diretrizes de Atenção à Reabilitação da Pessoa com Transtornos do Espectro do Autismo (TEA). Ministério da Saúde, Secretaria de Atenção à Saúde, Departamento de Ações Programáticas Estratégicas. Brasília, DF: Ministério da Saúde, 2014. 86 p., il. Disponível em:

https://bvsms.saude.gov.br/bvs/publicacoes/diretrizes_atencao_reabilitacao_pessoa_autismo.p df. Acesso em: 22 jan. 2020.

BRASIL. Base Nacional Comum Curricular (BNCC). Educação é a Base. Brasília: MEC/CONSED/UNDIME, 2017. Disponível em: http://basenacionalcomum.mec.gov.br Acesso em: 15 out. 2019.

COSTA, D. A. F. Superando limites: a contribuição de Vygotsky para a educação especial. Revista psicopedagogia, São Paulo, v. 23, n. 72, p. 232-240, 2006.

LIMA, S. M.; LAPLANE, A. L. F. A escolarização de alunos com autismo. Revista Brasileira de Educação Especial, v. 22, n. 2, p. 269-284, abr./jun. 2016.

MARTINS, A. D. F.; MONTEIRO, M. I. B. Alunos autistas: análise das possibilidades de interação social no contexto pedagógico. Psicologia Escolar e Educacional, São Paulo, v. 21, n. 2, p. 215-224, maio/ago. 2017.

PIMENTEL, A. G. L.; FERNANDES, F. D. M. A perspectiva de professores quanto ao trabalho com crianças com autismo. Audiol., Commun. Res., v. 19, n. 2, p. 171-178, 2014.

PINHO, M. A. Manifestações gastrointestinais em crianças com transtorno do espectro autista. 2015. 162 f. Tese (Doutorado em Processos Interativos dos Órgãos e Sistemas) Universidade Federal da Bahia, Salvador, 2015.

RODRIGUES, I. B; ANGELUCCI, C. B. Estado da arte da produção sobre escolarização de crianças diagnosticadas com TEA. Psicologia Escolar e educacional, São Paulo, v. 22, n. 3, p. 545-555, set./dez. 2018. 
SCHMIDT, C. et al. Inclusão escolar e autismo: uma análise da percepção docente e práticas pedagógicas. Revista Psicologia: Teoria e Prática, São Paulo, p. 222-235, jan./abr. 2016.

STOLTZ, T. As perspectivas construtivista e histórico-cultural na educação escolar. 3. ed. rev. e ampl. Curitiba: Ibpex, 2012.

TEIXEIRA, G. Manual dos Transtornos Escolares: entendendo os problemas de crianças e adolescentes a escola. Rio de Janeiro: BestSeller, 2013.

TREVIZAN, Z.; PESSOA, A. S. G. Psiquismo, linguagem e autismo: contribuições da semiótica nos contextos educativos. Educar em Revista, Curitiba, v. 34, n. 71, p. 241-258, set./out. 2018.

VARGAS, T. B. T; RODRIGUES, M. G. A. Mediação escolar: sobre habitar o entre. Revista Brasileira de Educação, Rio de Janeiro v. 23, p. 1-26, 2018.

VYGOTSKY, L. S. A formação social da mente. São Paulo: Martins Fontes, 1994.

VYGOTSKY, L. S. Pensamento e linguagem. São Paulo: Martins Fontes, 1998.

\section{Como referenciar este artigo}

SANTOS, W. O. dos; BRITO, A. G. C. de; FERREIRA; L. de S. Percepção docente sobre o atendimento ao estudante autista em escolas de Formosa-GO e Planaltina-DF. Doxa: Rev. Bras. Psico. e Educ., Araraquara, v. 22, n. 1, p. 31-46, jan./jun., 2020. e-ISSN: 2594-8385. DOI: https://doi.org/10.30715/doxa.v22i1.13304

Submetido em: 10/02/2020

Revisões requeridas em: $31 / 03 / 2020$

Aceito em: 30/04/2020

Publicado em: 01/06/2020 